\title{
Vitamin D status in pediatric patients with a history of malignancy
}

\author{
Dalit Modan-Moses ${ }^{1,2}$, Orit Pinhas-Hamiel ${ }^{1,2}$, Dafna Munitz-Shenkar ${ }^{3}$, Vered Temam ${ }^{3}$, Hannah Kanety ${ }^{2,4}$ and Amos Toren ${ }^{2,3}$
}

BACKGROUND: Multiple studies associate low vitamin D levels with cancer morbidity and mortality. However, few studies have measured vitamin D in pediatric patients with malignancy. Our aim was to assess vitamin D status in a large cohort of pediatric patients with cancer and to define risk factors for deficiency.

METHODS: Circulating 25-hydroxyvitamin D (25OHD) levels were measured in 211 patients. Calcium intake and sun exposure habits were assessed in 142 patients (age $12.1 \pm 5.8 \mathrm{y}$; number of male patients, 69; mean time from diagnosis, 4.4 $\pm 3.8 \mathrm{y})$.

RESULTS: Daily calcium intake was $66.2 \pm 39.3 \%$ of the recommended daily allowance. Mean 250HD levels were 20.6 $\pm 7.9 \mathrm{ng} / \mathrm{ml}$. Vitamin D deficiency $(<15 \mathrm{ng} / \mathrm{ml})$ was found in $24.6 \%$ of the patients and insufficiency $(15-20 \mathrm{ng} / \mathrm{ml})$ in $23.2 \%$. Younger age and amount of sun exposure were associated with higher serum 25OHD. No association was found with calcium intake, disease type, gender, BMI SD score, years since diagnosis, or stem cell transplantation. The $25 \mathrm{OHD}$ levels during winter were significantly lower than the summer levels.

CONCLUSION: The prevalence of vitamin D deficiency and insufficiency in pediatric patients with a history of malignancy was high, whereas calcium intake was low. These findings are concerning, given the risk for osteoporosis in this population and the possible role of vitamin $\mathrm{D}$ in the context of malignancy.

V itamin D plays a pivotal role in the physiological regulation of calcium and phosphate transport and bone mineralization. Traditionally, vitamin D deficiency was primarily considered in the context of rickets in children and osteomalacia in adults (1). However, a growing body of evidence suggests that vitamin D deficiency may be related to all-cause mortality as well as to disease onset or severity of many chronic illnesses including cardiovascular diseases, type II diabetes, infectious diseases, and autoimmune diseases such as type 1 diabetes and multiple sclerosis (2).

Vitamin D status is most reliably determined by measuring serum 25-hydroxyvitamin D (25OHD), however, there is a debate regarding optimal cutoff values (3). Interpretation of results and comparison between populations are further hampered by measurement issues-differences between automated immunoassays and chromatographic methods as well as between-laboratory variability (4).

Several lines of evidence suggest that vitamin $\mathrm{D}$ has a role in decreasing the risk of cancer. Numerous studies have linked decreased sunlight exposure to nonskin cancer incidence or survival or demonstrated an inverse association between vitamin D and its metabolites and cancer morbidity and mortality, particularly colorectal, breast, and prostate cancer $(1,3,5)$. Furthermore, high 25OHD and high vitamin D intake at the time of diagnosis and initiation of anticancer treatment were associated with improved overall and recurrence-free survival (6). These epidemiological and observational findings are supported by clinical trials showing reduced cancer incidence with vitamin $\mathrm{D}$ supplementation (7), and by laboratory studies showing that $1,25(\mathrm{OH})_{2} \mathrm{D}_{3}$ promotes cell differentiation, inhibits proliferation, and exhibits proapoptotic and anti-angiogenic properties $(3,8)$. Despite the wealth of data regarding vitamin $\mathrm{D}$ and cancer, only a handful of studies have assessed vitamin $\mathrm{D}$ status in pediatric patients with malignancy, and all included relatively small numbers of patients (Table 1) (9-19).

The aim of this study was to assess vitamin D status in a large cohort of pediatric patients with a history of malignancy and to identify potential risk factors for vitamin D deficiency. On the basis of the findings of previous studies, we hypothesized that the prevalence of vitamin $\mathrm{D}$ deficiency/insufficiency would be high and that 25OHD levels would be lowest among patients in the final stages of antineoplastic therapy because patients are instructed to avoid sun exposure during therapy.

\section{RESULTS}

\section{Patient Characteristics}

The 25OHD levels were available for 211 patients. Of these, 142 patients (69 males) actively participated in the study, i.e., we received signed, informed consent allowing access to the chart and the patients or their parents (for children younger than $11 \mathrm{y}$ of age) answered the questionnaire regarding calcium intake and sun exposure habits. The 25OHD levels of the other 69 patients were pooled with no clinical identifiers and used in the initial analysis to minimize selection bias, with the approval of the institutional Human Investigations Committee. 
Table 1. Previous studies assessing vitamin $D$ status in pediatric patients with cancer

\begin{tabular}{|c|c|c|c|c|c|}
\hline \multirow[b]{2}{*}{$N$} & \multirow[b]{2}{*}{ Disease } & \multicolumn{3}{|c|}{$25 \mathrm{OHD} n g / \mathrm{ml}^{\mathrm{a}}$} & \multirow[b]{2}{*}{ Reference } \\
\hline & & At Dg & During Tx & After Tx & \\
\hline 40 & ALL & $17.0 \pm 15.2$ & & & 9 \\
\hline 40 & ALL & \multicolumn{3}{|c|}{ "nl” but actually low } & 10 \\
\hline 48 & $\begin{array}{l}\text { ALL }=22 \\
\text { other }=26\end{array}$ & & & $13.6 \pm 7.2$ & 11 \\
\hline 28 & $\begin{array}{l}\mathrm{ALL}=10 \\
\text { solid }=18\end{array}$ & $12 \pm 4.4$ & $10 \pm 4.8$ & & 12 \\
\hline 31 & Wilm's tumor & & & 12 & 13 \\
\hline 59 & ALL & & & $\begin{array}{l}26.4 \pm 15.7 \\
29.4 \pm 12.9\end{array}$ & 14 \\
\hline 37 & ALL & $10(8.5,16.5)$ & & & 15 \\
\hline 20 & Lymphoma & $8.5(6.7-21)$ & $29(16-49)$ & $12(10-29)$ & 16 \\
\hline 70 & ALL & $21 \pm 7.8$ & & & 17 \\
\hline 78 & ALL & $26(21-33.2)$ & & & 18 \\
\hline 61 & Various & 17.6 & & & 19 \\
\hline
\end{tabular}

25OHD, 25-hydroxyvitamin D; ALL, acute lymphoblastic leukemia; Dg, diagnosis; $\mathrm{nl}$, normal; $\mathrm{Tx}$, treatment.

${ }^{2} 25 \mathrm{OHD}$ levels are presented as given in the original studies. Median levels were presented by some authors $(15,16,18,19)$, whereas other studies used mean values $(9,11,12,14,17)$. Some studies did not present SD values $(12,13)$ or interquartile ranges (19) for 25OHD. One paper (10) presented 25OHD levels only graphically. Levels originally given as $\mathrm{nmol} / \mathrm{l}(11,12)$ were converted to $\mathrm{ng} / \mathrm{ml}$

Table 2. Vitamin D status by gender, diagnosis, or having undergone stem cell transplantation

\begin{tabular}{lccc}
\hline & $n(\%)$ & $25 \mathrm{OHD}(\mathrm{ng} / \mathrm{ml})$ & $P$ value \\
\hline Male & $69(48.6)$ & $20.7 \pm 7.7$ & 0.933 \\
Female & $73(51.4)$ & $20.6 \pm 8.1$ & \\
SCT & $29(20.4)$ & $20.6 \pm 7.9$ & 0.973 \\
No SCT & $113(79.6)$ & $20.6 \pm 7.9$ & \\
Diagnosis & & & \\
$\quad$ Leukemia & $57(40.1)$ & $20.1 \pm 8.1$ & 0.37 \\
$\quad$ Lymphoma & $17(12)$ & $20.1 \pm 7.3$ & \\
$\quad$ Brain tumors & $32(22.5)$ & $23.1 \pm 8.3$ & \\
$\quad$ Solid tumor & $36(25.3)$ & $19.3 \pm 7.2$ & \\
GC & $85(60)$ & $20.2 \pm 7.7$ & 0.4 \\
No GC & $57(40)$ & $21.3 \pm 8.1$ & \\
Vitamin D & $12(8.5)$ & $20.3 \pm 7.0$ & 0.85 \\
No vitamin D & $130(91.5)$ & $20.7 \pm 8.0$ & \\
\hline
\end{tabular}

25OHD, 25-hydroxyvitamin D; GC, glucocorticoids; SCT, stem cell transplantation. aPatients received glucocorticoids as part of their treatment protocol. bPatients reported taking vitamin D supplements when blood sampling was performed.

The mean age of active participants at the time of $25 \mathrm{OHD}$ measurement was $12.1 \pm 5.8 \mathrm{y}$ (range 1.1-27.2 y, median 12.03), and the mean interval from diagnosis was $4.4 \pm 3.8 \mathrm{y}$ (range 6 wk to $21 \mathrm{y}$; median $3.39 \mathrm{y}$ ). Mean height SD score (SDS) was $-0.3 \pm 1.54$, significantly $(P=0.025)$ shorter than that expected in a normal population, probably indicating mild height compromise secondary to the underlying disease. Mean BMI SDS was $0.33 \pm 1.26$, significantly $(P=0.004)$ higher as compared

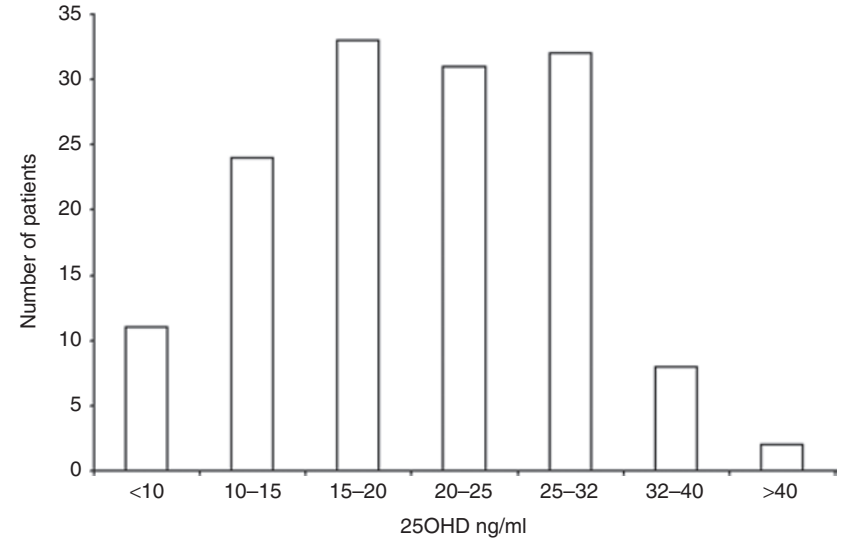

Figure 1. The distribution of $250 H D$ levels among the 142 active study participants. 25OHD, 25-hydroxyvitamin D.

with the expected value in a normal population. Data regarding diagnosis at presentation, stem cell or bone marrow transplantation, and treatment with glucocorticoids and vitamin D supplements are presented in (Table 2).

\section{Calcium Intake}

Mean reported dietary calcium intake was $759 \pm 421 \mathrm{mg} / \mathrm{d}$, corresponding to $66.2 \pm 39.3 \%$ of the recommended daily allowance (RDA) (20). Only $20.5 \%$ of the patients met the RDA for calcium intake.

\section{Serum 250HD Levels}

The distribution of 25OHD levels is presented in (Figure 1). Mean 25OHD levels were $20.6 \pm 7.9 \mathrm{ng} / \mathrm{ml}$. Thirty-five patients (24.6\%) were vitamin $\mathrm{D}$ deficient $(<15 \mathrm{ng} / \mathrm{ml})$, and another $33(23.2 \%)$ were vitamin D insufficient $(15-20 \mathrm{ng} / \mathrm{ml})$. Of the patients with $25 \mathrm{OHD}>20 \mathrm{ng} / \mathrm{ml}$, only 10 patients $(7 \%)$ had $25 \mathrm{OHD}$ levels $>32 \mathrm{ng} / \mathrm{ml}$. The $25 \mathrm{OHD}$ levels of patients not actively participating in the study were not significantly different from those of study participants, indicating no selection bias.

Serum 25OHD levels correlated positively with the amount of sun exposure $(r=0.195, P=0.02)$ (i.e., greater amount of sun exposure was associated with higher 25OHD). Of note, sun-protection score also correlated positively with $25 \mathrm{OHD}$ levels $(r=0.203, P=0.017)$.

As expected, plasma $25 \mathrm{OHD}$ levels varied significantly by season of blood collection. Levels in samples collected during the winter months $(18.1 \pm 7.7 \mathrm{ng} / \mathrm{ml})$ were significantly $(P<$ 0.001 ) lower as compared with levels obtained during summer $(23.7 \pm 7.3 \mathrm{ng} / \mathrm{ml})$. Accordingly, $37.2 \%$ of patients assessed during winter were vitamin D deficient and only $4.6 \%$ had $25 \mathrm{OHD}$ levels $>32 \mathrm{ng} / \mathrm{ml}$, as compared with $13.7 \%$ and $15.7 \%$ of patients assessed in summer (Figure 2). Younger age was associated with higher serum 25OHD levels $(r=-0.24, P=0.004)$.

On multivariable analysis, sun exposure (odds ratio $=-0.381$, $95 \% \mathrm{CI}=-0.597$ to $-0.164, P=0.001$ ), sun-protection score (odds ratio $=1.387,95 \% \mathrm{CI}=0.505-2.269, P=0.002)$, and younger age (odds ratio $=2.351,95 \% \mathrm{CI}=0.009-4.692, P=0.049$ ) remained independent significant predictors of $25 \mathrm{OHD}$ levels. 


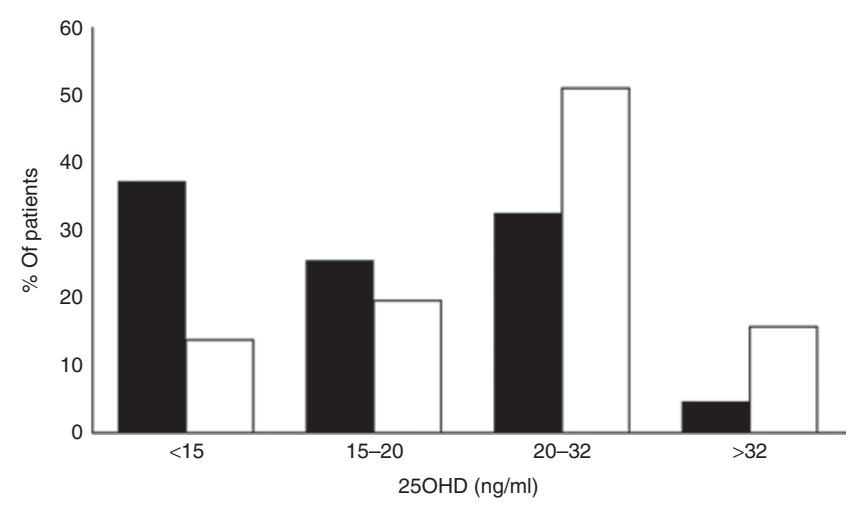

Figure 2. Vitamin $\mathrm{D}$ status according to season. Vitamin $\mathrm{D}$ deficiency $(<15 \mathrm{ng} / \mathrm{ml}$ ) was twice as common in the winter months (December, January, February; filled bars) than in summer months (June, July, August; open bars). Conversely, only $4.6 \%$ of patients assessed during winter had $25 \mathrm{OHD}$ levels $>32 \mathrm{ng} / \mathrm{ml}$ as compared with $15.7 \%$ of patients assessed during summer. 25OHD, 25-hydroxyvitamin D.

There was no association between 25OHD and disease type, gender, or having undergone stem cell transplantation (Table 2). No correlation was found between 25OHD and calcium intake, self-reported skin tone, and years since diagnosis. There was no association between weight status (assessed by BMI SDS) and 25OHD levels.

Serum calcium and 25OHD levels were not found to be correlated, and we did not observe hypocalcemia, hypophosphatemia, or hyperphosphatasia levels in patients with vitamin $\mathrm{D}$ deficiency.

Of note, the amount of sunlight exposure correlated positively with time from diagnosis $(r=0.252, P=0.003)$. There was no difference in $25 \mathrm{OHD}$ levels of patients who received glucocorticoids as compared with those who did not (20.2 \pm $7.7 \mathrm{ng} / \mathrm{ml}$ vs. $21.3 \pm 8.1 \mathrm{ng} / \mathrm{ml}$, respectively) (Table 2 ).

Twelve patients reported taking vitamin $\mathrm{D}$ supplements at the time blood sampling was performed. The 25OHD levels of patients taking supplements were not significantly different as compared with those in patients not taking supplements (Table 2).

\section{DISCUSSION}

In this study, we assessed vitamin D status in a large cohort of pediatric patients with a history of malignant disease. Our data indicate that these patients are at a very high risk for vitamin $\mathrm{D}$ deficiency and insufficiency. A fourth of our patients were vitamin D deficient $(<15 \mathrm{ng} / \mathrm{ml})$ and another $23 \%$ were vitamin D insufficient $(15-20 \mathrm{ng} / \mathrm{ml})$.

The definitions of what constitutes an appropriate vitamin D status are the subject of controversy. Our definitions were consistent with the conservative recommendations of the Lawson Wilkins Pediatric Endocrine Society (21) and the Institute of Medicine (20), on the basis of the stipulation that a minimum $25 \mathrm{OHD}$ level of $20 \mathrm{ng} / \mathrm{ml}$ is necessary to support and maintain all the classic actions of vitamin $\mathrm{D}$ on bone and mineral health. However, many experts advocate levels $>30 \mathrm{ng} / \mathrm{ml}$ to confer the beneficial nonskeletal health effects of vitamin D (3), and a level of $32 \mathrm{ng} / \mathrm{ml}$ is increasingly becoming accepted as the lower limit of normal for 25OHD levels in adults (21). Using these guidelines, only $7 \%$ of our patients had adequate $(>32 \mathrm{ng} / \mathrm{ml})$ 25OHD levels.

Several factors could explain low vitamin D levels in children with a history of malignancy. Patients are typically advised to avoid direct sunlight while undergoing chemotherapy because of the risk of photosensitivity and secondary skin neoplasm. In addition, patients may spend more time indoors as compared with their peers because of physical disability. Finally, poor diet and the toxic effects of chemotherapy and radiotherapy may affect vitamin $\mathrm{D}$ absorption.

Vitamin $\mathrm{D}$ is primarily made in the skin after exposure to ultraviolet radiation and $<10 \%$ is derived from dietary sources (21). Accordingly, serum 25OHD levels were positively correlated with self-reported amount of sun exposure. During winter, the 25OHD levels were significantly lower than those during summer, and the frequency of vitamin D deficiency during winter was twice as high. Similar results were reported by Sinha et al. (19) in children with a history of malignancy in the UK.

In our study, younger age was associated with higher serum $25 \mathrm{OHD}$ levels, consistent with the results of previous studies in healthy children (22). However, unlike other investigators (22-24), we did not find an association between 25OHD levels and weight status or gender. There was no association with calcium intake, self-reported skin tone, disease type, or having undergone stem cell transplantation. The amount of sunlight exposure was positively correlated with time from diagnosis, but there was no correlation between 25OHD levels and years since diagnosis.

Our results are consistent with the results of several smaller studies that estimated vitamin $\mathrm{D}$ status in pediatric patients with malignancy (Table 1) (9-19), showing that mean or median $25 \mathrm{OHD}$ levels were in the insufficiency range. Three of the aforementioned studies showed significantly lower levels of $25 \mathrm{OHD}$ in children with a history of malignancy as compared with normal controls $(16,17,19)$. In contrast, Simmons et al. (18) found 25OHD levels in acute lymphoblastic leukemia survivors to be similar to the levels in the normal US pediatric and adolescent population.

The high rates of vitamin D deficiency/insufficiency observed in our study were unexpected, because at the latitude in which Israel is located, UVB radiation is considered sufficient for vitamin D3 synthesis all year round (25). Data regarding vitamin D status in healthy Israeli children and adolescents are scant; however, two recent studies demonstrated 25OHD levels similar to those observed by us $(24,26)$. The prevalence of vitamin D deficiency and insufficiency in these studies and in our cohort was considerably higher than the reported prevalence in the US pediatric and adolescent population, in which only $9 \%$ were vitamin D deficient and 30\% had 25OHD levels $>29 \mathrm{ng} / \mathrm{ml} \mathrm{(22).}$ This may be partly explained by the fact that unlike in the United States, food fortification is not a practice in Israel-only low-fat milk and margarine are fortified with vitamin D (27).

Unfortunately, we were not able to include a healthy control group in this study. However, even if vitamin D status in our cohort was similar to that of their healthy peers, our findings 
are of particular concern considering the medical history of our patients. It has been suggested that adequate $25 \mathrm{OHD}$ levels at the time of cancer diagnosis may improve overall and recurrence-free survival $(6,28)$. Furthermore, survivors of childhood cancer are at risk of secondary neoplasms (29), reduced bone mineral density $(11,12,29)$, cardiovascular disease, and the metabolic syndrome (30), all of which have been associated with vitamin D deficiency/insufficiency.

About two-thirds of our patients received glucocorticoids as part of their treatment protocol, placing them at an increased risk for decreased bone density. Adequate calcium intake and maintenance of $25 \mathrm{OHD}$ levels above $20 \mathrm{ng} / \mathrm{ml}$ are considered essential in the treatment of decreased bone density in children and adolescents (31) and are important to achieve a maximal peak bone mass (32). In this respect, it is of concern that reported dietary calcium intake was low, amounting to only two-thirds of the RDA, and only a fifth of our patients met the recommendations for calcium intake. Similar results were observed by other investigators (17-19).

We consider our patients to be particularly vulnerable to the adverse effects of vitamin D deficiency and inadequate calcium intake. Hence, they deserve special attention, even if their vitamin D levels and calcium intake do not significantly differ from those of their peers, and are in need of nutritional intervention programs.

A possible limitation of our study is that due to limitations of our questionnaire and the medical record, we were unable to quantify more precisely vitamin $\mathrm{D}$ and calcium intake in the form of dietary supplements.

In conclusion, to our knowledge, this is the largest study to date to assess vitamin $\mathrm{D}$ status in pediatric patients with a history of malignancy, comprising a heterogeneous cohort with respect to both disease type and time from diagnosis. Children with a history of malignant disease are at a high risk (24.6\%) of being vitamin D deficient. A significant percentage of survivors did not attain the RDA for calcium via diet. For reasons relating to skeletal health, optimizing the calcium intake and vitamin D status of this group could be particularly advantageous. In view of the current evidence, it would seem prudent to ensure that a minimal $25 \mathrm{OHD}$ level of $20 \mathrm{ng} / \mathrm{ml}$ is maintained in pediatric patients with cancer. Intervention studies with vitamin $\mathrm{D}$ will help to address the issues of possible extraskeletal benefits of higher 25OHD serum levels.

\section{METHODS}

\section{Patients}

The study was undertaken in the pediatric hematology-oncology outpatient clinic at the Edmond and Lily Safra Children's Hospital, Chaim Sheba Medical Center, Ramat-Gan, Israel. This is a tertiary center, treating patients from all over Israel, which is $29^{\circ} 30^{\prime}-33.2^{\prime}$ north of the Equator. Serum 25OHD levels were obtained between 1 July 2010 and 1 February 2011 in all patients attending the clinic, as part of their routine visits. All patients were offered participation in this study, and after informed consent was given, patients or their parents (for children younger than $11 \mathrm{y}$ of age) were asked to answer a questionnaire regarding calcium intake and sun exposure habits. Demographic data including age, sex, time of diagnosis, disease type, and anticancer treatment were obtained from the patients' charts.
Patients were excluded from the study when we were unable to obtain consent (e.g., language barriers, patient attending clinic without parent/guardian) or if $25 \mathrm{OHD}$ levels were obtained before study initiation. The 25OHD levels of these patients were pooled with no clinical identifiers and were used in the initial analysis to minimize selection bias. Patients with low 25OHD levels were offered supplementation according to current recommendations and clinical judgment of the treating physician. The study was approved by the Human Investigations (Helsinki) Committee of the Sheba Medical Center, and informed consent was obtained from all participants or their parents (in the case of minors).

\section{Anthropometric Measurements}

Height and weight were obtained, and BMI was calculated based on the formula: weight $(\mathrm{kg}) /$ height $(\mathrm{m})^{2}$. Height, weight, and BMI SDS were calculated using age- and gender-specific growth data (based on the Centers for Disease Control and Prevention's Year 2000 Growth Charts) (http://www.cdc.gov/growthcharts). These data have been found adequate for assessing Israeli children (33).

\section{Laboratory Evaluation}

Serum calcium, phosphate, and alkaline phosphates were measured using an autoanalyzer (Olympus AU2700, Hamburg, Germany). Vitamin D levels were determined by the DiaSorin LIAISON competitive two-step chemiluminescent immunoassay (DiaSorin, Stillwater, MN).

The criteria used to determine vitamin $\mathrm{D}$ status were as follows: $25 \mathrm{OHD}$ levels $>20 \mathrm{ng} / \mathrm{ml}=$ sufficiency, $15-20 \mathrm{ng} / \mathrm{ml}=$ insufficiency, and $<15 \mathrm{ng} / \mathrm{ml}=$ deficiency (21). However, because a level of $32 \mathrm{ng} /$ $\mathrm{ml}$ is increasingly becoming accepted as the lower limit of normal for $25 \mathrm{OHD}$ levels in adults (21), data using this cutoff are presented as well.

\section{Dietary Evaluation}

Calcium intake was assessed using a self-administered food frequency questionnaire focusing on calcium-rich foods. This was a shortened version of a questionnaire used by the Israeli Ministry of Health in the First Israeli National Health and Nutrition Survey (MABAT YOUTH) (http://www.old.health.gov.il/download/pages/ mabat2007all.pdf). For the purpose of this study, we deleted from the original questionnaire those items that did not contribute to calcium intake.

\section{Sun Habits}

Sun exposure and sun-protection habits were evaluated using a validated questionnaire $(34,35)$. Forward/backward translations of the original questionnaire were completed by expert translators. Sun exposure was measured by asking the respondents to indicate the average number of hours they spent outdoors between $10 \mathrm{AM}$ and 4 PM both on weekdays and weekends. Sun-protection habits were assessed by measuring six protective behaviors (wearing a shirt with sleeves, wearing sunglasses, staying in the shade, using sunscreen, limiting time in the sun during midday, and wearing a hat) on a 4-point ordinal scale, and a composite sun-protection habits score was calculated by averaging responses to the six items (35).

\section{Season Definition}

The effect of seasonality on vitamin D levels was evaluated according to the month of the 25OHD test. Samples obtained during December through February were defined as "winter," and samples obtained during June through August were defined as "summer," corresponding to the months with the lowest and highest (respectively) levels of solar radiation observed in Israel (http://www.ims.gov.il/IMS/CLIMATE/ LongTermRadiation).

\section{Data Analysis}

The initial analysis included estimations of mean, SD, and frequency distribution. Comparisons between subgroups of patients (diagnosis group and treatment modalities) were made with the unpaired $t$-test or one-way ANOVA. To assess the correlations between 25OHD levels and age, BMI SDS, sun exposure and sun-protection habits, calcium intake, and years from diagnosis, we used the Pearson correlation test. Variables that showed significant association with 25OHD were used in a multivariable logistic regression with stepwise model 
selection. Results were considered significant if the two-sided $P$ value was $<0.05$. Calculations were performed using SPSS 15.0 , a statistical software package (SPSS, Chicago, IL).

\section{STATEMENT OF FINANCIAL SUPPORT}

The study was supported by the late Alter Jacob Israel and Layla Environment and Epidemiologic Research Foundation and the Israel Cancer Association.

\section{REFERENCES}

1. Deeb KK, Trump DL, Johnson CS. Vitamin D signalling pathways in cancer: potential for anticancer therapeutics. Nat Rev Cancer 2007;7:684700.

2. Pearce SH, Cheetham TD. Diagnosis and management of vitamin D deficiency. BMJ 2010;340:b5664.

3. Mullin GE, Dobs A. Vitamin $d$ and its role in cancer and immunity: a prescription for sunlight. Nutr Clin Pract 2007;22:305-22.

4. Binkley N, Krueger DC, Morgan S, Wiebe D. Current status of clinical 25-hydroxyvitamin D measurement: an assessment of between-laboratory agreement. Clin Chim Acta 2010;411:1976-82.

5. Boscoe FP, Schymura MJ. Solar ultraviolet-B exposure and cancer incidence and mortality in the United States, 1993-2002. BMC Cancer 2006;6:264.

6. Goodwin PJ, Ennis M, Pritchard KI, Koo J, Hood N. Prognostic effects of 25-hydroxyvitamin D levels in early breast cancer. J Clin Oncol 2009;27:3757-63.

7. Lappe JM, Travers-Gustafson D, Davies KM, Recker RR, Heaney RP. Vitamin $\mathrm{D}$ and calcium supplementation reduces cancer risk: results of a randomized trial. Am J Clin Nutr 2007;85:1586-91.

8. van Ginkel PR, Yang W, Marcet MM, et al. 1 a-hydroxyvitamin D2 inhibits growth of human neuroblastoma. J Neurooncol 2007;85:255-62.

9. Halton JM, Atkinson SA, Fraher L, et al. Mineral homeostasis and bone mass at diagnosis in children with acute lymphoblastic leukemia. J Pediatr 1995; 126:557-64.

10. Halton JM, Atkinson SA, Fraher L, et al. Altered mineral metabolism and bone mass in children during treatment for acute lymphoblastic leukemia. J Bone Miner Res 1996;11:1774-83.

11. Arikoski P, Kröger H, Riikonen P, Parviainen M, Voutilainen R, Komulainen J. Disturbance in bone turnover in children with a malignancy at completion of chemotherapy. Med Pediatr Oncol 1999;33:455-61.

12. Arikoski P, Komulainen J, Riikonen P, Voutilainen R, Knip M, Kröger H. Alterations in bone turnover and impaired development of bone mineral density in newly diagnosed children with cancer: a 1-year prospective study. J Clin Endocrinol Metab 1999;84:3174-81.

13. Othman F, Guo CY, Webber C, Atkinson SA, Barr RD. Osteopenia in survivors of Wilms tumor. Int J Oncol 2002;20:827-33.

14. Alikasifoglu A, Yetgin S, Cetin M, et al. Bone mineral density and serum bone turnover markers in survivors of childhood acute lymphoblastic leukemia: comparison of megadose methylprednisolone and conventionaldose prednisolone treatments. Am J Hematol 2005;80:113-8.

15. Marinovic D, Dorgeret S, Lescoeur B, et al. Improvement in bone mineral density and body composition in survivors of childhood acute lymphoblastic leukemia: a 1-year prospective study. Pediatrics 2005;116:e102-8.

16. El-Ziny MA, Al-Tonbary YA, Salama OS, Bakr A, Al-Marsafawy H, Elsharkawy AA. Low bone mass in children with malignant lymphoma. Pediatr Hematol Oncol 2007;24:577-85.
17. Gunes AM, Can E, Saglam H, Ilçöl YO, Baytan B. Assessment of bone mineral density and risk factors in children completing treatment for acute lymphoblastic leukemia. J Pediatr Hematol Oncol 2010; 32:e102-7.

18. Simmons JH, Chow EJ, Koehler E, et al. Significant 25-hydroxyvitamin D deficiency in child and adolescent survivors of acute lymphoblastic leukemia: treatment with chemotherapy compared with allogeneic stem cell transplant. Pediatr Blood Cancer 2011;56:1114-9.

19. Sinha A, Avery P, Turner S, Bailey S, Cheetham T. Vitamin D status in paediatric patients with cancer. Pediatr Blood Cancer 2011;57:594-8.

20. Institute of Medicine. Dietary Reference Intakes for Calcium and Vitamin D. Washington, DC: National Academies Press, 2011

21. Misra M, Pacaud D, Petryk A, Collett-Solberg PF, Kappy M; Drug and Therapeutics Committee of the Lawson Wilkins Pediatric Endocrine Society. Vitamin D deficiency in children and its management: review of current knowledge and recommendations. Pediatrics 2008;122:398-417.

22. Kumar J, Muntner P, Kaskel FJ, Hailpern SM, Melamed ML. Prevalence and associations of 25-hydroxyvitamin D deficiency in US children: NHANES 2001-2004. Pediatrics 2009;124:e362-70.

23. Mansbach JM, Ginde AA, Camargo CA Jr. Serum 25-hydroxyvitamin D levels among US children aged 1 to 11 years: do children need more vitamin D? Pediatrics 2009;124:1404-10.

24. Oren Y, Shapira Y, Agmon-Levin N, et al. Vitamin D insufficiency in a sunny environment: a demographic and seasonal analysis. Isr Med Assoc J 2010;12:751-6.

25. Tsiaras WG, Weinstock MA. Factors influencing vitamin D status. Acta Derm Venereol 2011;91:115-24.

26. Saliba W, Rennert HS, Kershenbaum A, Rennert G. Serum 25(OH)D concentrations in sunny Israel. Osteoporos Int 2012;23:687-94.

27. Kaluski DN, Tulchinsky TH, Haviv A, et al. Addition of essential micronutrients to foods-implication for public health policy in Israel. Isr Med Assoc J 2003;5:277-80.

28. Drake MT, Maurer MJ, Link BK, et al. Vitamin D insufficiency and prognosis in non-Hodgkin's lymphoma. J Clin Oncol 2010;28:4191-8.

29. Tylavsky FA, Smith K, Surprise H, et al. Nutritional intake of longterm survivors of childhood acute lymphoblastic leukemia: evidence for bone health interventional opportunities. Pediatr Blood Cancer 2010;55:1362-9.

30. van Waas M, Neggers SJ, Pieters R, van den Heuvel-Eibrink MM. Components of the metabolic syndrome in 500 adult long-term survivors of childhood cancer. Ann Oncol 2010;21:1121-6.

31. Bachrach LK, Ward LM. Clinical review 1: bisphosphonate use in childhood osteoporosis. J Clin Endocrinol Metab 2009;94:400-9.

32. Rizzoli R, Bianchi ML, Garabédian M, McKay HA, Moreno LA. Maximizing bone mineral mass gain during growth for the prevention of fractures in the adolescents and the elderly. Bone 2010;46:294-305.

33. Goldstein A, Haelyon U, Krolik E, Sack J. Comparison of body weight and height of Israeli schoolchildren with the Tanner and Centers for Disease Control and Prevention growth charts. Pediatrics 2001;108:E108.

34. Glanz K, Yaroch AL, Dancel M, et al. Measures of sun exposure and sun protection practices for behavioral and epidemiologic research. Arch Dermatol 2008;144:217-22.

35. Glanz K, Schoenfeld ER, Steffen A. A randomized trial of tailored skin cancer prevention messages for adults: Project SCAPE. Am J Public Health 2010;100:735-41. 